\title{
Complication rates for preexisting baclofen pumps and ventricular shunts following scoliosis correction: a preliminary study
}

\author{
Jonathan Dallas, BS, ${ }^{1}$ Katherine D. Sborov, BA, ${ }^{1}$ Bradley S. Guidry, BS, ${ }^{1}$ Silky Chotai, MD,,${ }^{1,2}$ and \\ Christopher M. Bonfield, MD1,2
}

1Surgical Outcomes Center for Kids, Monroe Carell Jr. Children's Hospital at Vanderbilt; and ²Department of Neurosurgery,
Vanderbilt University Medical Center, Nashville, Tennessee

OBJECTIVE Many patients undergoing spinal fusion for neuromuscular scoliosis have preexisting neurosurgical implants, including ventricular shunts (VSs) for hydrocephalus and baclofen pumps (BPs) for spastic cerebral palsy. Recent studies have discussed a possible increase in implant complication rates following spinal fusion, but published data are inconclusive. The authors therefore, sought to investigate: 1) the rate of implant complications following fusion, 2) possible causes of these complications, and 3) factors that place patients at higher risk for implant-related complications.

METHODS Cases involving pediatric patients with a preexisting VS or BP who underwent spinal fusion for scoliosis correction between 2005 and 2016 at a single tertiary children's hospital were retrospectively analyzed. Patient demographics, implant characteristics, spinal fusion details, neurosurgical follow-up, and implant complications in the 180 days following fusion were recorded and analyzed.

RESULTS Overall, 75 patients who underwent scoliosis correction had preexisting implants: 39 had BPs, 31 VSs, and 5 both. The patients' mean age at fusion was $13.49 \pm 2.78$ years (range 3.62-18.81 years), and the mean time from the most recent previous implant surgery to fusion was $5.70 \pm 4.65$ years (range $0.10-17.3$ years). The mean preoperative and postoperative Cobb angles were $62.4^{\circ} \pm 18.9^{\circ}$ degrees (range $20.9^{\circ}-109.0^{\circ}$ ) and $23.5^{\circ} \pm 13.3^{\circ}$ degrees (range $\left.2.00^{\circ}-67.3^{\circ}\right)$, respectively. No VS complications were identified. Two patients with BPs were found to have complications (unintentional cutting of their BP catheter during posterior spinal fusion) within 180 days postfusion. There were no recorded neurosurgical implant infections, failures, fractures, or dislodgements. Although 10 patients required at least 1 surgical procedure for irrigation and debridement of the spine wound following fusion, there were no abdominal or cranial implant wound infections requiring revision, and no implants required removal.

CONCLUSIONS The results of this study suggest that spinal fusion for scoliosis correction does not increase the rates of complications involving previously placed neurosurgical implants. A large-scale, prospective, multicenter study is needed to fully explore and confirm this finding.

https://thejns.org/doi/abs/10.3171/2018.2.PEDS17713

KEYWORDS hydrocephalus; cerebral palsy; scoliosis; ventriculoperitoneal shunt; baclofen pump; spinal fusion; spine

$\mathrm{B}$ Отн hydrocephalus and cerebral palsy are often associated with a number of comorbid conditions, such as spina bifida and spinal deformity. ${ }^{15,17}$ The most notable of these deformities is scoliosis, a condition that is characterized by a $>10^{\circ}$ lateral curvature of the spine. ${ }^{13}$ There are a number of treatments for scoliosis; in more severe cases, it may be treated with a spinal fusion.
In these cases, a spinal construct is formed to maintain the spine in a more linear fashion. ${ }^{3,5}$

Because patients may have hydrocephalus and/or cerebral palsy in addition to scoliosis, a number of patients undergo ventricular shunt (VS) and/or intrathecal baclofen pump (BP) placement and subsequent spinal fusion. Recent studies and case reports have shown a possible relation-

ABBREVIATIONS BP = baclofen pump; I\&D = irrigation and debridement; IV = intravenous; OR = operating room; VS = ventricular shunt; VUMC = Vanderbilt University Medical Center.

SUBMITTED December 19, 2017. ACCEPTED February 27, 2018.

INCLUDE WHEN CITING Published online May 4, 2018; DOI: 10.3171/2018.2.PEDS17713. 
ship between spinal fusion and increased implant failure in patients with preexisting implants. . $^{1,4,6,7,9-12,15,18}$ Common causes of implant failures include infection, malfunction, obstruction, and catheter fracture..$^{2,16}$ A number of hypotheses have been proposed to explain a relationship with spinal fusion; for example, causes of shunt failure have been hypothesized to include newly introduced mechanical stress, growth-related stress, and surgical technique. ${ }^{15}$

Previous publications in this area have primarily been case reports, hypothesizing the potentially increased risk of neurosurgical implant complications after spinal fusion surgery. Few large studies have quantitatively analyzed the association between scoliosis fusion and failure of preexisting neurosurgical implants. Therefore, we sought to use retrospective analysis to 1) investigate the rate of implant complications related to scoliosis fusion, 2) analyze causes of implant complications, and 3) find factors that place patients at higher risk for implant-related complications.

\section{Methods}

A total of 75 pediatric patients with neuromuscular scoliosis who underwent fusions between August 2005 and August 2016 at Monroe Carell Jr. Children's Hospital were retrospectively selected from available billing information and chart review. Inclusion criteria selected for patients who 1) received surgical treatment (posterior arthrodesis/posterior segmental instrumentation) for scoliosis at Vanderbilt University Medical Center (VUMC), 2) had a minimum of 6 months of follow-up care at VUMC, and 3) had received an implant prior to their scoliosis fusion.

Data collected for each patient included patient demographics, implant history (prior to scoliosis fusion), spinal fusion information, and postoperative follow-up. Patient demographics included date of birth, sex, race, ethnicity, and insurance status. Implant history encompassed the type and side of the implant(s), the date of the most recent implant procedure, and the type of operation. Information regarding the spinal fusion included the date of the surgery, vertebral levels fused, side of the major Cobb angle, pre- and postoperative Cobb angle measurements, and postoperative complications (including details of postoperative spine wound complications/infections). All Cobb angles were measured using upright spinal radiographs at the most recent date prior to fusion (preoperative) and the earliest date following fusion (postoperative). Finally, follow-up information included any returns to the operating room (OR) within 180 days, the indication for the return to the OR, and information about the patient's next neurosurgical operation (if applicable).

\section{Results}

Overall, 793 posterior spinal fusions were performed at Monroe Carell Junior Children's Hospital from August 2005 to August 2016. Of these, 75 (9.5\%) were performed on patients with preexisting baclofen pumps and/or ventricular shunts. Demographics for this cohort are shown in Table 1.

Of the 75 included patients, 31 had solely a ventricular shunt (VS), 39 had solely an intrathecal baclofen pump (BP), and 5 had both. In total, 69/75 (92.0\%) had their
TABLE 1. Patient demographics

\begin{tabular}{lc}
\hline \multicolumn{1}{c}{ Characteristic } & No. of Pts (\%) \\
\hline Sex & $32(42.7 \%)$ \\
\hline Male & $43(57.3 \%)$ \\
\hline Female & $1(1.3 \%)$ \\
\hline Ethnicity & $71(94.7 \%)$ \\
\hline Hispanic or Latino & $3(4.0 \%)$ \\
\hline Not Hispanic or Latino & \\
\hline Unknown/unreported & $1(1.3 \%)$ \\
\hline Race & $1(1.3 \%)$ \\
\hline American Indian or Alaska native & $8(10.7 \%)$ \\
\hline Asian & $0(0.0 \%)$ \\
\hline Black or African American & $65(86.7 \%)$ \\
\hline Native Hawaiian or other Pacific Islander & $0(0.0 \%)$ \\
\hline White & $0(0.0 \%)$ \\
\hline Unknown/unreported & \\
\hline Other & $59(78.7 \%)$ \\
\hline Insurance & $16(21.3 \%)$ \\
\hline Public
\end{tabular}

Pts = patients.

most recent implant surgery prior to scoliosis correction performed at our institution. Table 2 reports information regarding the implant characteristics for both VSs and BPs. In all, there were $36 \mathrm{VSs}$, almost all of which were ventriculoperitoneal shunts (97.2\%), and there were 44 BPs. For both VSs and BPs, a majority of implants were

TABLE 2. Implant characteristics

\begin{tabular}{cc}
\hline Characteristic & No. of Cases (\%) \\
\hline Shunt & $36(48.0 \%)$ \\
\hline Type & $35(97.2 \%)$ \\
\hline Ventriculoperitoneal & $1(2.8 \%)$ \\
\hline Ventriculoatrial & $22(61.1 \%)$ \\
\hline Side & $12(33.3 \%)$ \\
\hline Right & $2(5.6 \%)$ \\
\hline Left & $19(52.8 \%)$ \\
\hline Both & $15(41.7 \%)$ \\
\hline Concavity & $2(5.6 \%)$ \\
\hline Concave & $44(58.7 \%)$ \\
\hline Convex & \\
\hline Both & $38(86.4 \%)$ \\
\hline Pump & $6(13.6 \%)$ \\
\hline Side & $19(43.2 \%)$ \\
\hline Right & $25(56.8 \%)$ \\
\hline Left &
\end{tabular}


TABLE 3. Implant indications

\begin{tabular}{cc}
\hline \multicolumn{1}{c}{ Implant \& Indication } & No. of Cases $(\%)$ \\
\hline Shunt & \\
\hline Spina bifida & $14(38.9 \%)$ \\
\hline Congenital hydrocephalus & $7(19.4 \%)$ \\
\hline IVH & $5(13.9 \%)$ \\
\hline Trauma & $3(8.3 \%)$ \\
\hline Infection & $2(5.6 \%)$ \\
\hline Lissencephaly & $1(2.8 \%)$ \\
\hline Achondroplasia & $1(2.8 \%)$ \\
\hline Pfeiffer syndrome & $1(2.8 \%)$ \\
\hline Idiopathic intracranial HTN & $1(2.8 \%)$ \\
\hline Unknown & $1(2.8 \%)$ \\
\hline Pump & \\
\hline Cerebral palsy, nontraumatic & $40(90.9 \%)$ \\
\hline Cerebral palsy, traumatic & $4(9.1 \%)$ \\
\hline
\end{tabular}

HTN = hypertension; IVH = intraventricular hemorrhage.

placed on the patient's right side. There were more VSs placed on the concave side of the patient's scoliosis curvature, whereas BPs were more commonly placed on the convex side.

The indications for implant placement are shown in Table 3. For VS placement, the most common indications were spina bifida, congenital hydrocephalus, intraventricular hemorrhage, trauma, and infection. A large majority (90.9\%) of the BPs were placed due to nontraumatic cerebral palsy.

Information about each patient's most recent implant operation (prior to spinal fusion) is provided in Table 4. For a majority of VSs, there was a revision following initial placement of the shunt. On the other hand, a majority of BPs did not require revision. Patients were followed routinely by neurosurgery for VS and BP care. No additional implant-related follow-up was provided prior to or after the spine fusion.

A summary of characteristics related to the spinal fusion procedures is provided in Table 5. The patients' mean age at spinal fusion was $13.49 \pm 2.78$ years (range $3.62-$ 18.81 years), and the fusion procedure was performed an average of 5.70 years (SD 4.65 years, range $0.10-17.3$ years) after their most recent implant operation. The mean preoperative and postoperative Cobb angles were $62.4^{\circ}$ $\pm 18.9^{\circ}$ (range $20.9^{\circ}-109.0^{\circ}$ ) and $23.5^{\circ} \pm 13.3^{\circ}$ (range $2.00^{\circ}-67.3^{\circ}$ ), respectively, resulting in an average Cobb angle change of $38.92^{\circ}$. The average number of vertebral levels fused was 14.20. In all cases, patients had both thoracic and lumbar vertebrae fused. Ten patients (13.3\%) required postoperative irrigation and debridement (I\&D) of their spinal wound; however, no implants needed to be removed, and no I\&D of cranial or abdominal wounds was required. Of note, spine fusion cases follow a standard surgical-site infection reduction protocol at our institution, and these cases are tracked.

A list of patients requiring I\&D following posterior spinal fusion is provided in Table 6. Of these, 7 patients had VSs and 3 had BPs, and half of the cases included subfas-
TABLE 4. Implant operation information

\begin{tabular}{lc}
\hline \multicolumn{1}{c}{ Variable } & Value \\
\hline Most recent procedure type & \\
\hline New shunt insertion & $12(16.0 \%)$ \\
\hline Shunt revision & $17(22.7 \%)$ \\
\hline Shunt insertion following infection & $3(4.0 \%)$ \\
\hline New baclofen pump & $29(38.7 \%)$ \\
\hline Pump revision & $14(18.7 \%)$ \\
\hline Age at most recent implant surgery, yrs & \\
\hline Mean (SD) & $7.79(5.23)$ \\
\hline Median (IQR) & $8.88(2.55-11.41)$ \\
\hline
\end{tabular}

$\mathrm{IQR}=$ interquartile range.

cial involvement. Of note, in 2 cases, the BP catheter was seen during the I\&D; however, neither patient required revision, removal, or replacement of the pump. In one of these 2 cases, cultures were positive for coagulase-negative Staphylococcus, and in the other they demonstrated methicillin-resistant $S$. aureus. The patient in the first of these 2 cases was treated with 2 I\&D procedures, 8 weeks of intravenous (IV) vancomycin and rifampin, followed by 6 months of oral trimethoprim/sulfamethoxazole and rifampin. The second patient required 3 I\&D procedures, 8

\section{TABLE 5. Scoliosis surgery characteristics}

\begin{tabular}{|c|c|}
\hline Characteristic & Value \\
\hline \multicolumn{2}{|l|}{ Age at scoliosis surgery, yrs } \\
\hline Mean (SD) & $13.49(2.78)$ \\
\hline Median (IQR) & $13.32(11.78-15.40)$ \\
\hline \multicolumn{2}{|c|}{ Time btwn last implant \& spine surgery, yrs } \\
\hline Mean (SD) & $5.70(4.65)$ \\
\hline Median (IQR) & $4.41(2.11-8.00)$ \\
\hline \multicolumn{2}{|l|}{ Preop major Cobb angle } \\
\hline Mean (SD) & $62.39^{\circ}\left(18.93^{\circ}\right)$ \\
\hline Median (IQR) & $59.50^{\circ}\left(50.80^{\circ}-72.75^{\circ}\right)$ \\
\hline \multicolumn{2}{|l|}{ Side of major curve } \\
\hline Right & $34(45.3 \%)$ \\
\hline Left & $41(54.7 \%)$ \\
\hline \multicolumn{2}{|l|}{ Spinal areas fused } \\
\hline Cervical & $0(0 \%)$ \\
\hline Thoracic & $75(100 \%)$ \\
\hline Lumbar & $75(100 \%)$ \\
\hline \multicolumn{2}{|l|}{ No. of levels fused } \\
\hline Mean (SD) & $14.20(2.20)$ \\
\hline Median (IQR) & $15.00(14.00-15.00)$ \\
\hline \multicolumn{2}{|l|}{ Postop major Cobb angle } \\
\hline Mean (SD) & $23.47^{\circ}\left(13.29^{\circ}\right)$ \\
\hline Median (IQR) & $20.80^{\circ}\left(12.65^{\circ}-33.90^{\circ}\right)$ \\
\hline \multicolumn{2}{|l|}{ Change in Cobb angle } \\
\hline Mean (SD) & $38.92^{\circ}\left(14.10^{\circ}\right)$ \\
\hline Median (IQR) & $37.40^{\circ}\left(27.45^{\circ}-50.15^{\circ}\right)$ \\
\hline
\end{tabular}


TABLE 6. I\&Ds following posterior spinal fusion

\begin{tabular}{rcccc}
\hline $\begin{array}{c}\text { Case } \\
\text { No. }\end{array}$ & $\begin{array}{c}\text { Implant } \\
\text { Type }\end{array}$ & $\begin{array}{c}\text { Subfascial } \\
\text { Involvement }\end{array}$ & $\begin{array}{c}\text { Implant } \\
\text { Involvement }\end{array}$ & $\begin{array}{c}\text { Implant Replaced } \\
\text { or Removed }\end{array}$ \\
\hline 1 & Shunt & Yes & No & No \\
\hline 2 & Shunt & No & No & No \\
\hline 3 & Shunt & No & No & No \\
\hline 4 & Shunt & Yes & No & No \\
\hline 5 & Shunt & No & No & No \\
\hline 6 & Shunt & Yes & No & No \\
\hline 7 & Shunt & No & No & No \\
\hline 8 & Pump & No & No & No \\
\hline 9 & Pump & Yes & Yes & No \\
\hline 10 & Pump & Yes & Yes & No \\
\hline
\end{tabular}

weeks of IV vancomycin, and 8 months of oral levofloxacin and rifampin. All 7 patients were initially treated with a course of IV antibiotics and then transitioned to longerterm oral antibiotics. After discharge, they were followed in both spine and infectious disease outpatient clinics.

Table 7 shows all follow-up implant operations that were performed within 180 days of spinal fusion. No patient had VS complications and 2 patients had BP complications related to spinal fusion (unintended BP catheter cutting during posterior spinal fusion, which required intraoperative repair, in both cases). In each of these cases, the BP catheter was violated during exposure of the spine. When the complication was identified, a new catheter was inserted into the intrathecal space and connected to the end of the previous catheter leading to the generator. The fusion operation was then continued to completion. Four other pump operations were planned (catheter repositioning or pump replacement for end of generator life) and are not considered complications of the spinal fusion. There were no cases of baclofen withdrawal, baclofen overdose, CSF leak, or cranial or abdominal wound revisions.

\section{Discussion}

Patients who receive neurosurgical implants, including VSs and BPs, often have a number of comorbid conditions. One of the most common of these conditions is scoliosis, which may occur due to a variety of factors in many patients with spina bifida or cerebral palsy.,15 In turn, such patients often are treated with spinal fusion to aid in scoliosis correction.

Prior studies have presented evidence of an increase in neurosurgical implant failure rates following neuromuscular scoliosis correction. For example, Caird et al. provided evidence that spinal fusion increases the rate of $\mathrm{BP}$ failure, and Lai et al. provided a series of cases pertaining to shunt failure. ${ }^{7,15}$ More recently, Hatano et al. reported a $21 \%$ shunt complication rate following spinal fusion. ${ }^{11} \mathrm{~A}$ number of hypotheses have been proposed for this relationship; these include mechanical stress, aged or brittle implants, and surgical technique. ${ }^{15}$ However, prior evidence has not been consistent; both Borowski et al. and Yaszay et al. found that posterior spinal fusion did not increase complication rates in baclofen pumps. ${ }^{6,18}$
TABLE 7. Shunt or pump operations within 180 days following scoliosis correction

\begin{tabular}{lcc}
\hline \multicolumn{1}{c}{ Operation } & $\begin{array}{c}\text { Within } \\
\text { 90 Days }\end{array}$ & $\begin{array}{c}\text { Within } \\
180 \text { Days }\end{array}$ \\
\hline Shunt & 0 & 0 \\
\hline$\quad$ Reoperations & & \\
\hline Pump & 2 & 2 \\
\hline$\quad$ Catheter repair due to unintentional cutting & 1 & 1 \\
\hline$\quad$ Catheter repositioning (planned) & 0 & 3 \\
\hline$\quad$ Replacement (battery end of life) & \\
\hline $\begin{array}{l}\text { Values represent numbers of operations. } \\
\text { * Marked as complication of scoliosis fusion. Repair of catheter completed } \\
\text { during scoliosis correction operation. }\end{array}$
\end{tabular}

In the present study, 6 of the 75 included patients required some form of implant revision within 180 days of their spinal fusion. Only 2 of these revisions were considered to be potential spinal fusion complications, as 3 patients needed baclofen pump revisions due to battery end-of-life, and 1 patient had an intraoperative revision that was planned prior to scoliosis correction. Our study indicates that implant failure rates are not significantly higher following spinal fusion. However, increased care, especially during the exposure portion of the procedure, must be undertaken. Due to the low failure rate in our study, potential underlying causes of implant failure (such as time between surgeries, age at fusion, number of levels fused, and Cobb angle change) could not be analyzed.

There are a number of reasons why the failure rate following spinal fusion may not be higher than the general implant failure rate. It could be that changes to the integrity of the implant or newly placed mechanical stress are simply not notable enough to cause functional failure of the device. Additionally, it may be that the surgical technique regarding implant placement is accommodating of future spinal fusion, such as through the placement of excess shunt tubing. It is important to note that although the overall rate of VS failure is decreasing compared to historical controls, there remains a baseline rate of failure in the natural history of VS in the overall population. ${ }^{14}$ Although we did not observe VS failure in the 36 patients with VSs, it is likely this is due to the small size of our overall cohort.

One important statistic to note is that the patients in this study had a large number of wound complications following spinal fusion. Specifically, 10 patients (13.3\%) required at least $1 \mathrm{I} \& \mathrm{D}$ procedure, which is consistent with the range of 5\%-20\% reported for infection rates in neuromuscular scoliosis fusions in the literature. ${ }^{8}$ In our 10 cases, half of the infections were suprafascial only. In two of the cases in which I\&D was required, BP pump catheters were seen in the field. The catheters were left in place, and fortunately, no subsequent removal or revision was required. All patients who required I\&D received an initial course of IV antibiotics, and transitioned to longerterm oral antibiotics.

It is also important to note that many surgeons intentionally cut the BP catheter in the initial stages of the 
scoliosis correction operation and reconnect it at the end of the case. However, this is not the standard practice at our institution, due to concern over baclofen withdrawal or lack of baclofen relief in the initial postoperative period due to interruption of baclofen infusion during the surgery. We suggest that the pump tubing be left intact during the spine surgery if possible.

This study is not without limitations, the most notable of which being the sample size. In this study, there were only 2 patients who were deemed to have an unexpected implant failure within 180 days of spinal fusion. Given that 2 cases were identified in our study cohort of 75 patients, assuming a case-control study design and power of 0.80 , we would need over 3500 controls to properly assess the impact of spinal fusion on implant failure. It is difficult to find a large number of similar patients at any one institution; accordingly, a large, multicenter study including high-volume institutions, would be needed to convincingly determine the impact of spinal fusion on implant failure.

\section{Conclusions}

In conclusion, our study suggests that patients with previously placed neurosurgical implants are not at increased risk for implant failure following spinal fusion for scoliosis correction. While additional surgical caution must be used to avoid damage to the implant structure and functional integrity, spinal fusions can still be performed safely in this group of patients. Further large-scale, multicenter studies should be performed to validate this finding.

\section{References}

1. Alden TD, Lytle RA, Park TS, Noetzel MJ, Ojemann JG: Intrathecal baclofen withdrawal: a case report and review of the literature. Childs Nerv Syst 18:522-525, 2002

2. Awaad Y, Rizk T, Siddiqui I, Roosen N, McIntosh K, Waines GM: Complications of intrathecal baclofen pump: prevention and cure. ISRN Neurol 2012:575168, 2012

3. Benson ER, Thomson JD, Smith BG, Banta JV: Results and morbidity in a consecutive series of patients undergoing spinal fusion for neuromuscular scoliosis. Spine (Phila Pa 1976) 23:2308-2317, discussion 2318,1998

4. Blakeney WG, D'Amato C: Ventriculoperitoneal shunt fracture following application of halo-gravity traction: a case report. J Pediatr Orthop 35:e52-e54, 2015

5. Boachie-Adjei O, Lonstein JE, Winter RB, Koop S, vanden Brink K, Denis F: Management of neuromuscular spinal deformities with Luque segmental instrumentation. J Bone Joint Surg Am 71:548-562, 1989

6. Borowski A, Shah SA, Littleton AG, Dabney KW, Miller F: Baclofen pump implantation and spinal fusion in children: techniques and complications. Spine (Phila Pa 1976) 33:1995-2000, 2008

7. Caird MS, Palanca AA, Garton H, Hensinger RN, Ayyangar RN, Drongowski A, et al: Outcomes of posterior spinal fusion and instrumentation in patients with continuous intrathecal baclofen infusion pumps. Spine (Phila Pa 1976) 33:E94-E99, 2008
8. Cognetti D, Keeny HM, Samdani AF, Pahys JM, Hanson DS, Blanke K, et al: Neuromuscular scoliosis complication rates from 2004 to 2015: a report from the Scoliosis Research Society Morbidity and Mortality database. Neurosurg Focus 43(4):E10, 2017

9. Fernandes P, Dolan L, Weinstein SL: Intrathecal baclofen withdrawal syndrome following posterior spinal fusion for neuromuscular scoliosis: a case report. Iowa Orthop J 28:77-80, 2008

10. Geiger F, Parsch D, Carstens C: Complications of scoliosis surgery in children with myelomeningocele. Eur Spine J 8:22-26, 1999

11. Hatano H, Kawakami N, Tsuji T, Ohata T, Saito T, Tauchi R, et al: Ventriculoperitoneal shunt complications and scoliosis surgery. Childs Nerv Syst 32:2019-2020, 2016 (Abstract)

12. Hoover D, Ganju A, Shaffrey CI, Bartkowski H, Rauzzino MJ: Shunt fracture following correction of spinal deformity. Case illustration. J Neurosurg 92 (1 Suppl):122, 2000

13. Kim H, Kim HS, Moon ES, Yoon CS, Chung TS, Song HT, et al: Scoliosis imaging: what radiologists should know. Radiographics 30:1823-1842, 2010

14. Kulkarni AV, Riva-Cambrin J, Butler J, Browd SR, Drake JM, Holubkov R, et al: Outcomes of CSF shunting in children: comparison of Hydrocephalus Clinical Research Network cohort with historical controls: clinical article. J Neurosurg Pediatr 12:334-338, 2013

15. Lai LP, Egnor MR, Carrion WV, Haralabatos SS, Wingate MT: Ventricular peritoneal shunt malfunction after operative correction of scoliosis: report of three cases. Spine J 14:e5e8, 2014

16. Sainte-Rose C, Piatt JH, Renier D, Pierre-Kahn A, Hirsch JF, Hoffman HJ, et al: Mechanical complications in shunts. Pediatr Neurosurg 17:2-9, 1991/1992

17. Tsirikos AI: Development and treatment of spinal deformity in patients with cerebral palsy. Indian J Orthop 44:148-158, 2010

18. Yaszay B, Scannell BP, Bomar JD, Sponseller PD, Shah SA, Asghar J, et al: Although inconvenient, baclofen pumps do not complicate scoliosis surgery in patients with cerebral palsy. Spine (Phila Pa 1976) 40:E504-E509, 2015

\section{Disclosures}

The authors report no conflict of interest concerning the materials or methods used in this study or the findings specified in this paper.

\section{Author Contributions}

Conception and design: Bonfield. Acquisition of data: Dallas, Sborov, Chotai. Analysis and interpretation of data: Bonfield, Dallas. Drafting the article: Dallas, Sborov. Critically revising the article: Bonfield, Dallas, Guidry. Reviewed submitted version of manuscript: all authors. Approved the final version of the manuscript on behalf of all authors: Bonfield. Administrative/technical/material support: Guidry. Study supervision: Bonfield.

\section{Correspondence}

Christopher M. Bonfield: Vanderbilt University Medical Center, Nashville, TN. chris.bonfield@vanderbilt.edu. 